\title{
PVP-Stabilized Palladium Nanoparticles in Silica as Effective Catalysts for Hydrogenation Reactions
}

\author{
Caroline Pires Ruas, Daiane Kessler Fischer, and Marcos Alexandre Gelesky \\ Laboratory Catalysis and Inorganic Synthesis, School of Chemistry and Food, Federal University of Rio Grande, Avenue Itália, Km 08 , \\ 96201-900 Rio Grande, RS, Brazil \\ Correspondence should be addressed to Marcos Alexandre Gelesky; marcosgelesky@furg.br
}

Received 9 August 2013; Accepted 11 November 2013

Academic Editor: John A. Capobianco

Copyright (C) 2013 Caroline Pires Ruas et al. This is an open access article distributed under the Creative Commons Attribution License, which permits unrestricted use, distribution, and reproduction in any medium, provided the original work is properly cited.

\begin{abstract}
Palladium nanoparticles stabilized by poly (N-vinyl-2-pyrrolidone) $(\mathrm{PVP})$ can be synthesized by corresponding $\mathrm{Pd}(\mathrm{acac})_{2}(\mathrm{acac}=$ acetylacetonate) as precursor in methanol at $80^{\circ} \mathrm{C}$ for $2 \mathrm{~h}$ followed by reduction with $\mathrm{NaBH}_{4}$ and immobilized onto $\mathrm{SiO}_{2}$ prepared by sol-gel process under acidic conditions ( $\mathrm{HF}$ or $\mathrm{HCl}$ ). The PVP/Pd molar ratio is set to 6 . The effect of the sol-gel catalyst on the silica morphology and texture and on $\mathrm{Pd}(0)$ content was investigated. The catalysts prepared $\left(c a .2 \% \mathrm{Pd}(0) / \mathrm{SiO}_{2} / \mathrm{HF}\right.$ and $c a .0,3 \%$ $\mathrm{Pd}(0) / \mathrm{SiO}_{2} / \mathrm{HCl}$ ) were characterized by TEM, FAAS, and SEM-EDS. Palladium nanoparticles supported in silica with a size $6.6 \pm$ $1.4 \mathrm{~nm}$ were obtained. The catalytic activity was tested in hydrogenation of alkenes.
\end{abstract}

\section{Introduction}

Poly (N-vinyl-2-pyrrolidone) stabilized metal nanoparticles have attracted considerable interest when it comes to preventing coagulation and precipitation of the metal nanoparticles. Polymer protecting agents allow preparation of metal colloids that can be stable for months with reasonable control over size as well as shape [1]. The nanoparticles are kinetically unstable with respect to aggregation or the bulk metal and should be stabilized by electrostatic or steric protection $[2,3]$. Some of the protecting agents provide steric stabilization such as surfactants [4], ionic liquids [5-8], and polyoxoanions [9]. Their main disadvantage, however, is the problematic separation of the catalytic particles from the product and unused reactants at the end of the reaction. Immobilization of the particles on a solid support can facilitate the separation process, but may simultaneously lead to a decrease in activity. The nanoparticle synthesis involves addition of a polymer to the metal salt followed by chemical or thermal reduction to produce a stable black suspension of $\operatorname{Pd}(0)$ particles. The types of stabilizers and concentration, the solvent polarity [10], and the aging time of colloidal suspensions [11] can have an effect on the size, shape and catalytic activity of palladium nanoparticles. Platinum nanoparticles protected by PVP have been synthesized by alcohol reduction methods and incorporated into mesoporous SBA-15 silica during hydrothermal synthesis [12]. There have been several very recent reports in the literature of the catalytic properties of nanoparticles of $\mathrm{Ag}[13,14]$, Rh [15], Pt [16, 17] and Pd [18] in PVP. Palladium colloid solutions stabilized by poly(N-vinyl-2-pyrrolidone) can be used as catalysts with high reactivity in C-C bond formation microwave-assisted reactions as shown by Heck [19] and Suzuki [20]. Catalytic hydrogenation reactions have been extensively evaluated with metal nanoparticles [21, 22]. We were successful in applying the new method for the synthesis of PVP-stabilized palladium (0) nanoparticles and immobilized in $\mathrm{SiO}_{2}$ employing the solgel process as catalysts for hydrogenation reactions. The mean diameters of the palladium nanoparticles are determined by TEM. The aim of this study is to examine the catalytic activity in hydrogenation of alkenes.

\section{Experimental Section}

2.1. General. Palladium(II) acetylacetonate $\left(\mathrm{Pd}(\mathrm{acac})_{2}\right)$, poly (N-vinyl-2-pyrrolidone) (PVP-55, average molecular weight 55.000), and sodium borohydride (98\%) were purchased from Sigma-Aldrich (Brazil). Pd/C (5\%) was provided by Degussa (Brazil). Methanol was purchased from Synth and 
used as received. All other chemicals were purchased from commercial sources and used without further purification. All solutions were prepared with double deionized water. Gas chromatography analysis was performed with an Rtx$5(30 \mathrm{~m} \times 0,25 \mathrm{~mm} \times 0,25 \mu \mathrm{m})$ gas chromatograph with an FID detector and a $30 \mathrm{~m}$ capillary column with $5 \%$ phenyl and $95 \%$ dimethylpolysiloxane as the carrier gas and the $\mathrm{N}_{2}(2,2 \mathrm{~mL} / \mathrm{min})$. The nanoparticle formation and hydrogenation reactions were carried out in a modified FischerPorter bottle immersed in a silicone oil bath and connected to a hydrogen tank. The temperature was maintained at $75^{\circ} \mathrm{C}$ by a hot-stirring plate connected to a digital controller (ETS-D4 IKA) with stirring at $1200 \mathrm{rpm}$. The fall in the hydrogen pressure in the tank was monitored with a pressure transducer interfaced through a Novus converter to a PC and the data workup via Microcal Origin 5.0.

2.2. Palladium Nanoparticles Solution. The suspensions of palladium nanoparticles were prepared by the alcohol reduction method [23]. The Palladium nanoparticles solution was prepared from a solution containing $\mathrm{Pd}(\mathrm{acac})_{2}(30 \mathrm{mg}$, $0.1 \mathrm{mmol})$ and it was dissolved in methanol $(10 \mathrm{~mL})$ and poly(N-vinyl-2-pyrrolidone (33 $\mathrm{mg}, 0.6 \mathrm{mmol}$ of monomeric units, Mw 55.000) as a stabilizer. Sodium borohydride ( $20 \mathrm{mg}, 0.6 \mathrm{mmol}$ ) was then added after reflux. The solution was refluxed for $2 \mathrm{~h}$, resulting in a dark brown solution. The color change from yellow to dark indicates that the formation of palladium nanoparticles was completed.

\subsection{Synthesis of Palladium Nanoparticles Immobilized in} Silica. Silica immobilized $\operatorname{Pd}(0)$ nanoparticles were prepared by the sol-gel process under acidic conditions. Typical procedure: the $\operatorname{Pd}(0)$ nanoparticles solution (prepared in Section 2.2) was introduced in a Becker under vigorous stirring for 10 minutes and $2 \mathrm{~mL}$ of tetraethoxy orthosilicate ( $2 \mathrm{~g}, 9 \mathrm{mmol}$ ) was then added. The acid solution (HF or $\mathrm{HCl}$ ) was introduced in a Becker under vigorous stirring at $50^{\circ} \mathrm{C}$. The temperature was kept at $50^{\circ} \mathrm{C}$ and left to stand for a further $24 \mathrm{~h}$. The resulting material was isolated by centrifugation ( $3000 \mathrm{rpm}$ for $5 \mathrm{~min}$ ) and washed several times with water and methanol and dried under vacuum.

2.4. Adsorption and Desorption Isotherms. The specific surface area analysis and pore size distribution of the samples was performed in a Gemini analyzer (Micromeritics Tristar 3020). The adsorption data was obtained at liquid-N2 temperature. The $100 \mathrm{mg}$ of samples were preheated at $150^{\circ} \mathrm{C}$ for $4 \mathrm{~h}$ under vacuum. Specific area was assessed by the BET method. Average pore diameter and its distribution were obtained by BJH method.

2.5. Hydrogenations Reactions. The catalysts $(50 \mathrm{mg})$ were placed in a Fischer-Porter bottle and the alkene (1 g) was added. The reactor was placed in an oil bath at $75^{\circ} \mathrm{C}$ and hydrogen was admitted to the system at constant pressure (4 atm) under stirring until the consumption of hydrogen stopped. The organic products were recovered by decantation and analyzed by GC. The reuse of the catalysts was performed by simple extraction of the organic phase (upper phase) followed by the addition of the alkenes.

2.6. Scanning Electron Microscopy (SEM) and Electron Dispersive Spectroscopy (EDS) Elemental Analysis. The morphology of the materials was analyzed by SEM using a JEOL model JSM 6060 with $20 \mathrm{kV}$ and 5000 magnification and the electron dispersive spectroscopy (EDS) analysis was performed using a JEOL model JSM 5800 with $20 \mathrm{kV}$ and 5000 magnification. The same instrument was used for the EDS with a Noran detector $(20 \mathrm{kV}$ with an acquisition time of $100 \mathrm{~s}$ and 5000 magnification).

2.7. Sample Preparation and TEM Analysis. The morphologies of the obtained particles were determined on a JEOL JEM-2010 equipped with an EDS system and a JEOL JEM120 EXII electron microscope, operating at accelerating voltages of $120 \mathrm{kV}$. The TEM samples were prepared by deposition of the $\mathrm{Pd}(0)$ nanoparticles or $\mathrm{Pd}(0) / \mathrm{SiO}_{2} / \mathrm{HF}$ isopropanol dispersions on a carbon-coated copper grid at room temperature. The histograms of the nanoparticles size distributions were obtained from the measurement of around 300 diameters (palladium nanoparticles) and 600 diameters $\left(\mathrm{Pd}(0) / \mathrm{SiO}_{2} / \mathrm{HF}\right)$ and reproduced in different regions of the $\mathrm{Cu}$ grid assuming spherical shapes.

2.8. Flame Atomic Absorption (FAAS). The Palladium present in the $\mathrm{Pd}(0) / \mathrm{SiO}_{2} / \mathrm{HF}$ was measured using an Analytik Jena (Jena, Germany) flame atomic absorption spectrometer, equipped with a deuterium background correction system and a transversely heated graphite atomizer, using an airacetylene $\left(10: 2.5 \mathrm{~L} \mathrm{~min}^{-1}\right)$ flame under optimized conditions. Pyrolytically coated graphite tubes, hollow cathode lamp (operated at $3 \mathrm{~mA}$ ), and deuterium lamp were supplied by Analytik Jena. Hollow cathode lamps of Pd $(\lambda) 247.6 \mathrm{~nm}$ ) from the same manufacturer were used as radiation sources.

\section{Results and Discussion}

The sol-gel process allows us to obtain solid products by creating an oxide network via progressive polycondensation reactions of molecular precursors in a liquid medium. The process essentially consists of two steps: hydrolysis and condensation. Both reactions are affected by the nature of the catalyst [24]. Therefore, in the present study, two main acids were evaluated: $\mathrm{HF}$ or $\mathrm{HCl}$. The textural properties were further characterized by nitrogen adsorption. Specific area, pore diameter, and pore volume were calculated by the BET method (Table 1). The pore volume was shown to be dependent of the acidic conditions ( $\mathrm{HF}$ or $\mathrm{HCl}$ ). Nevertheless, the pore diameter was shown to be smaller for the materials prepared in the presence of $\mathrm{HCl}$ as catalyst (entry 2). The investigation of the palladium elemental concentrations in the catalytic samples is shown in Table 1 . The concentrations of incorporated $\mathrm{Pd}(0)$ was determined using FAAS. The concentrations are expressed as $\%(\mathrm{~m} / \mathrm{m})$. It is evident that the $\operatorname{Pd}(0)$ metal concentration increased for the materials prepared in the presence of HF as catalysts (entry 1). 


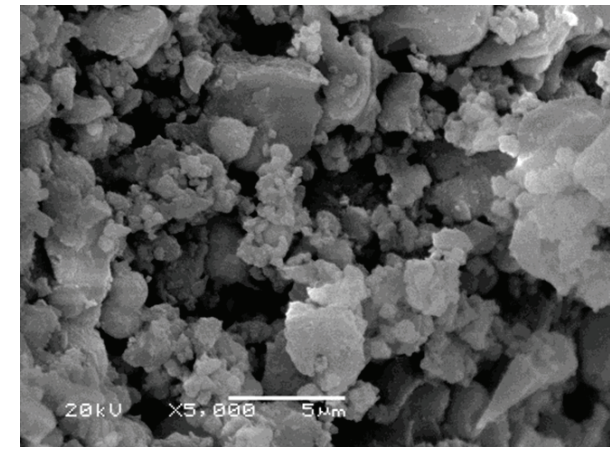

(a)

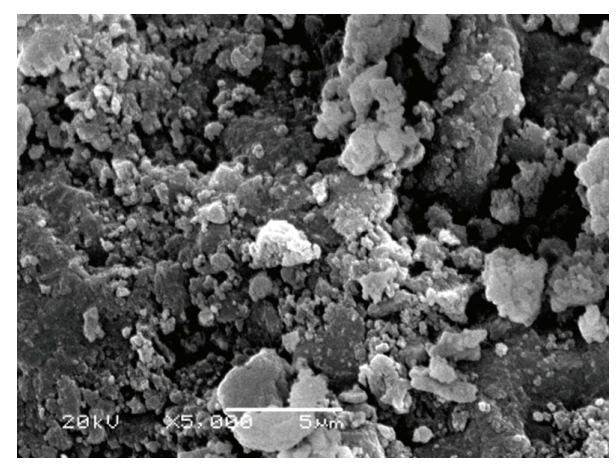

(b)

Figure 1: Micrographs obtained by SEM of the resulting xerogels: (a) $\mathrm{Pd}(0) / \mathrm{SiO}_{2} / \mathrm{HF}$ and (b) $\mathrm{Pd}(0) / \mathrm{SiO}_{2} / \mathrm{HCl}$.

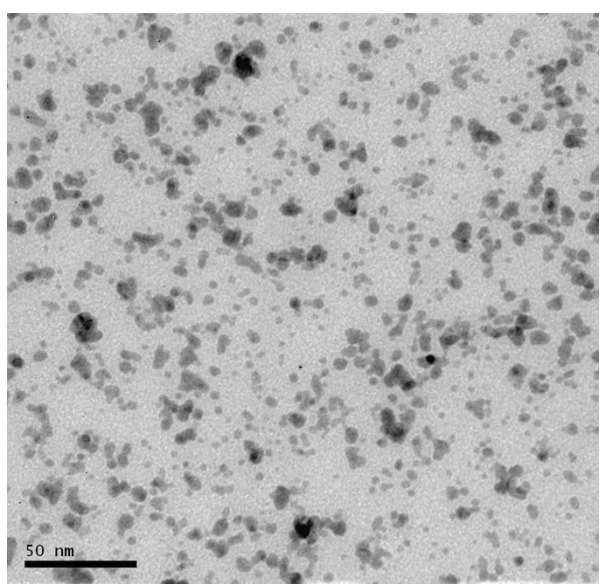

(a)

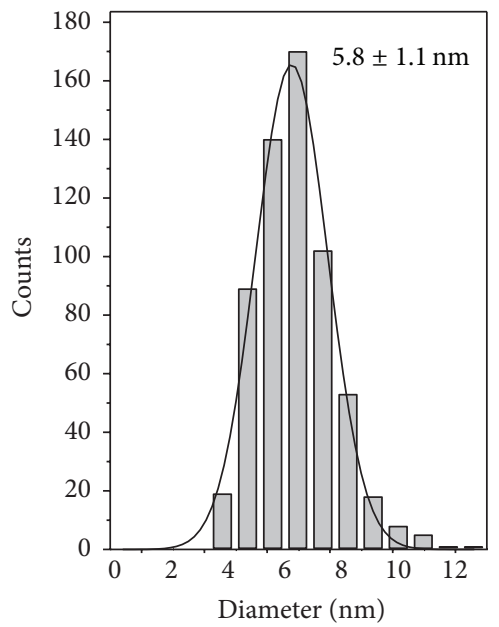

(b)

FIgURE 2: (a) TEM micrographs showing the $\mathrm{Pd}(0)$ nanoparticles solution observed at $120 \mathrm{kV}$. (b) Histogram illustrating the particle size distribution.

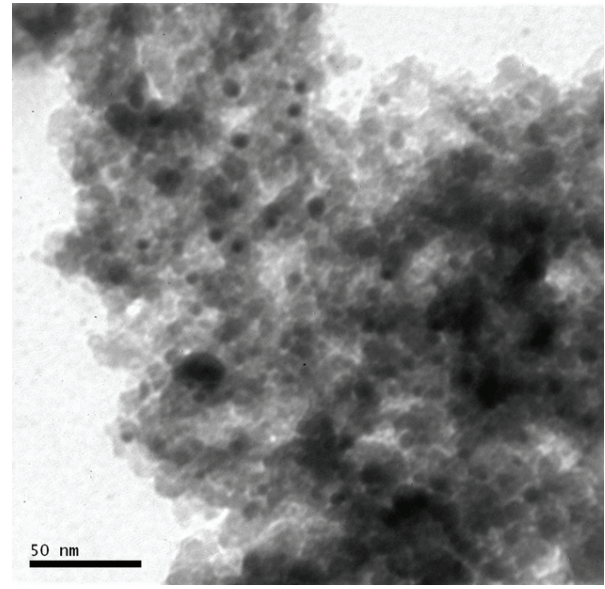

(a)

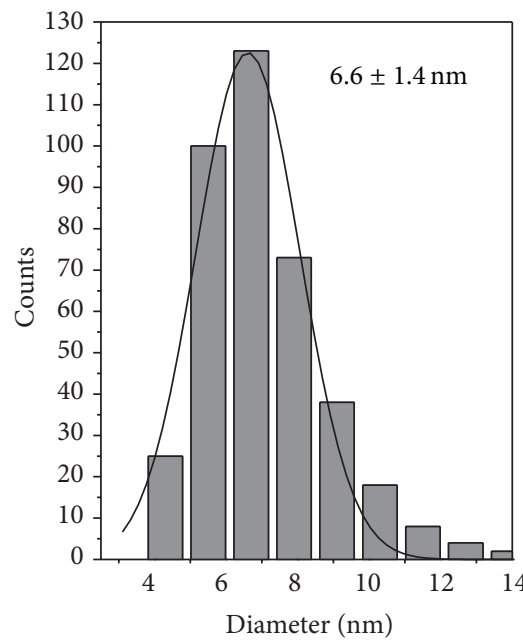

(b)

Figure 3: (a) TEM micrographs showing the $\mathrm{Pd}(0)$ nanoparticles to $\mathrm{Pd}(0) / \mathrm{SiO}_{2} / \mathrm{HF}$ observed at $120 \mathrm{kV}$. (b) Histogram illustrating the particle size distribution. 
TABLE 1: Textural properties of the xerogel ${ }^{\mathrm{a}}$.

\begin{tabular}{|c|c|c|c|c|c|}
\hline Entry & Sample & $S_{\mathrm{BET}} / \mathrm{m}^{2} \mathrm{~g}^{-1}$ & $V_{p} / \mathrm{cm}^{3} \mathrm{~g}^{-1}$ & $D_{p} / \mathrm{nm}$ & FAAS (\%) \\
\hline 1 & $\mathrm{Pd}(0) / \mathrm{SiO}_{2} / \mathrm{HF}$ (as prepared) & 254 & 0.005 & 12 & 2.0 \\
\hline 2 & $\mathrm{Pd}(0) / \mathrm{SiO}_{2} / \mathrm{HCl}$ (as prepared) & 634 & 0.03 & 2 & 0.3 \\
\hline 3 & $\mathrm{Pd}(0) / \mathrm{SiO}_{2} / \mathrm{HF}$ (soxhlet) & 328 & 0.009 & 7 & - \\
\hline 4 & $\mathrm{Pd}(0) / \mathrm{SiO}_{2} / \mathrm{HF}$ (calcined) & 225 & 0.005 & 14 & - \\
\hline
\end{tabular}

${ }^{\mathrm{a}} S_{\mathrm{BET}}$ : specific area determined by BET method, $V_{p}$ : pore volume, and $d_{p}$ : pore diameter.

TABLE 2: Hydrogenation of alkenes at 4 atm of $\mathrm{H}_{2}{ }^{\mathrm{a}}$.

\begin{tabular}{|c|c|c|c|c|}
\hline Entry & Cat. & Alkene & $t / \mathrm{min}^{\mathrm{b}}$ & $\mathrm{TOF}^{\mathrm{c}}$ \\
\hline 1 & $\mathrm{Pd}(0) / \mathrm{SiO}_{2} / \mathrm{HF}^{\mathrm{d}}$ & 1-hexene & 12 & 158 \\
\hline 2 & $\mathrm{Pd}(0) / \mathrm{SiO}_{2} / \mathrm{HF}^{\mathrm{e}}$ & 1-decene & 10 & 74 \\
\hline 3 & $\mathrm{Pd}(0) / \mathrm{SiO}_{2} / \mathrm{HF}^{\mathrm{f}}$ & cyclohexene & 49 & 60 \\
\hline 4 & $\mathrm{Pd}(0) / \mathrm{SiO}_{2} / \mathrm{HCl}^{\mathrm{g}}$ & 1-hexene & 31 & 425 \\
\hline 5 & $\mathrm{Pd}(0) / \mathrm{SiO}_{2} / \mathrm{HCl}^{\mathrm{h}}$ & 1-decene & 35 & 189 \\
\hline 6 & $\mathrm{Pd} / \mathrm{C}(5 \%)$ & 1-decene & 6 & 8 \\
\hline
\end{tabular}

${ }^{\mathrm{a}}$ Reaction conditions: temperature $75^{\circ} \mathrm{C}$, constant hydrogen pressure $(4 \mathrm{~atm})$, solvent less. ${ }^{\mathrm{b}}$ Time for $100 \%$ conversion. ${ }^{\mathrm{c}} \mathrm{TOF}$ based on total metal (mmol hydrogenated product formed per mmol of Pd per minute) for $20 \%$ conversion. ${ }^{\mathrm{d}} \mathrm{Pd}(0) / \mathrm{SiO}_{2} / \mathrm{HF}(50 \mathrm{mg}, 2.0 \%$ of $\mathrm{Pd}(0)), 12 \mathrm{mmol}$ of alkene. ${ }^{\mathrm{e}} \mathrm{Pd}(0) / \mathrm{SiO}{ }_{2} / \mathrm{HF}$ (50 mg, 2.0\% of $\mathrm{Pd}(0)), 7 \mathrm{mmol}$ of alkene. ${ }^{\mathrm{f}} \mathrm{Pd}(0) / \mathrm{SiO}_{2} / \mathrm{HF}(50 \mathrm{mg}, 2.0 \%$ of $\mathrm{Pd}(0)), 12 \mathrm{mmol}$ of alkene. ${ }^{\mathrm{g}} \mathrm{Pd}(0) / \mathrm{SiO}_{2} / \mathrm{HCl}(50 \mathrm{mg}, 0.3 \%$ of $\mathrm{Pd}(0)), 12 \mathrm{mmol}$ of alkene. ${ }^{\mathrm{h}} \mathrm{Pd}(0) / \mathrm{SiO}_{2} / \mathrm{HCl}(50 \mathrm{mg}, 0.3 \%$ of $\mathrm{Pd}(0)), 7 \mathrm{mmol}$ of alkene. ${ }^{\mathrm{g}} \mathrm{Pd} / \mathrm{C}(50 \mathrm{mg}, 5.0 \%$ of $\mathrm{Pd}(0)), 7 \mathrm{mmol}$ of alkene.

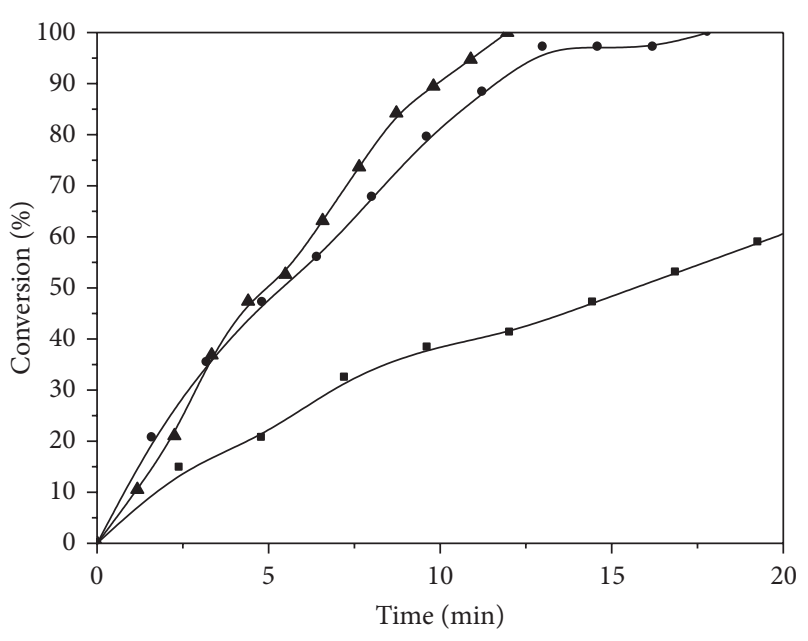

FIgURE 4: Hydrogenation of 1-hexene (•), 1-decene $(\mathbf{\Delta})$, and cyclohexene $(\boldsymbol{\square})$ by $\mathrm{Pd}(0) / \mathrm{SiO}_{2} / \mathrm{HF}$ under 4 atm of $\mathrm{H}_{2}$ (constant pressure) at $75^{\circ} \mathrm{C}$, and [alkene] $/[\mathrm{Pd}(0)]=1279$ to 1 -hexene, 752 to 1 -decene and 1290 to cyclohexene.

The metal distribution was determined by SEM-EDS analyses. Mapping showed a homogeneous $\operatorname{Pd}(0)$ distribution in the silica grains, for the materials prepared in the presence of $\mathrm{HF}$ as catalysts. Figure 1 illustrates the micrography of samples prepared by acids.

According to Figure 1, particle morphologies are in accordance to that usually observed for pure silica synthesized by these acid-catalyzed conditions. In this case a less organized, plate-like structure was observed for both cases.

Figure 2(a) shows the micrograph of the isolated $\operatorname{Pd}(0)$ particles, the mean size was shown to be $c a .5 .8 \pm 1.1 \mathrm{~nm}$ with irregularly shaped.
In the case of $\mathrm{Pd}(0) / \mathrm{SiO}_{2} / \mathrm{HF}$ prepared by acid catalysis $(\mathrm{HF})$, both the morphology and size (ca. $6.6 \pm 1.4 \mathrm{~nm})$ were maintained within the silica framework (Figure 3). It is clear that the morphological structure of the nanoparticles did not change with the presence of silica.

The supported catalysts were evaluated in hydrogenation reactions 1-hexene, 1-decene and cyclohexene hydrogenation reactions (Figure 4). For comparative purposes, the data concerning the catalytic activity of commercial Pd/C (5\%) (Table 2) was also included.

As shown in Table 2, all the supported systems were more active exhibiting higher TOF in comparison to those of commercial $\mathrm{Pd} / \mathrm{C}(5 \%)$. The structure generated in $\mathrm{Pd}(0) / \mathrm{SiO}_{2} / \mathrm{HCl}$ might have afforded more active systems because the immobilized $\mathrm{Pd}$ content is less than $\mathrm{Pd}(0) / \mathrm{SiO}_{2} / \mathrm{HF}$. Besides, according to porosimetric measurements, the pore diameter was much smaller for the $\mathrm{Pd}(0) / \mathrm{SiO}_{2} / \mathrm{HCl}$ system.

Finally, the catalytic material $\mathrm{Pd}(0) / \mathrm{SiO}_{2} / \mathrm{HF}$ can be recovered by simple decantation and reused for at least nine times without any significant loss in catalytic activity (Figure 5).

\section{Conclusion}

The palladium nanoparticles protected with PVP were successfully supported in silica prepared by sol gel process (acid catalysis). The $\operatorname{Pd}(0)$ content in the resulting xerogels was shown to be dependent of the preparative route. In particular the silica-based systems prepared under acidic conditions (HF) were shown to be the most active and stable. The use of $\mathrm{Pd}(0) / \mathrm{SiO}_{2} / \mathrm{HF}$ as catalysts in hydrogenation of alkenes gives better yields and TOF values under moderate conditions and shorter reaction times. Recycling experiments show that 


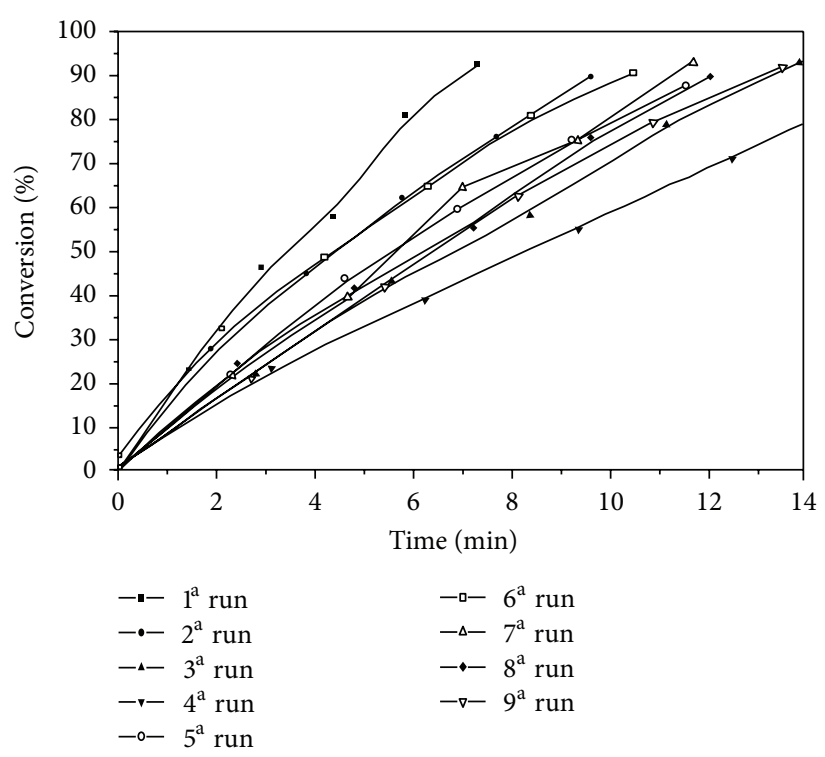

(a)

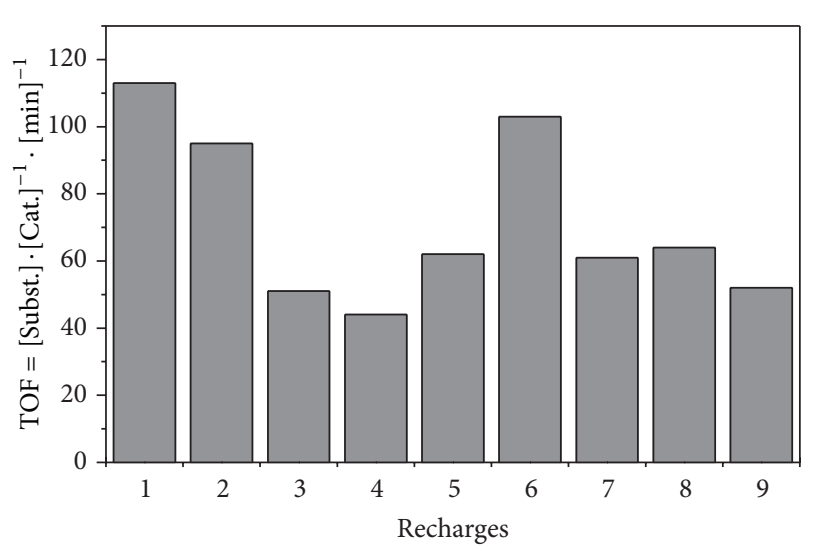

FIGURE 5: Recycling experiments for the hydrogenation of 1-hexene. Conditions: $100 \mathrm{mg} \mathrm{of} \mathrm{Pd}(0) / \mathrm{SiO} / \mathrm{HF}(\mathrm{ca} .2 \%), 1-\mathrm{hexene}(1 \mathrm{~g}, 12 \mathrm{mmol})$, 4 atm of $\mathrm{H}_{2}$ (constant pressure), temperature $75^{\circ} \mathrm{C}$.

$\mathrm{Pd}(0) / \mathrm{SiO}_{2} / \mathrm{HF}$ could be used nine times with essentially no loss in activity for the hydrogenation of 1-hexene. The palladium nanoparticles/silica combination exhibits an excellent synergistic effect that enhances the activity and durability of the catalyst for the hydrogenation of alkenes.

\section{Conflict of Interests}

The authors declare that there is no conflict of interests regarding the publication of this paper.

\section{Acknowledgments}

The authors would like to thank CAPES for partial financial support and PPGQTA for scholarships. They would also like to thank Prof. Dr. Jairton Dupont (UFRGS) and CMEUFRGS for the TEM and SEM microscopy analyses. They would also like to thank Dr. Fábio Andrei Duarte (UFSM) for performing the FAAS analysis.

\section{References}

[1] T. Teranishi and M. Miyake, "Size control of palladium nanoparticles and their crystal structures," Chemistry of Materials, vol. 10, no. 2, pp. 594-600, 1998.

[2] J. D. Aiken III and R. G. Finke, "A review of modern transitionmetal nanoclusters: their synthesis, characterization, and applications in catalysis," Journal of Molecular Catalysis A, vol. 145, no. 1-2, pp. 1-44, 1999.

[3] A. Roucoux, J. Schulz, and H. Patin, "Reduced transition metal colloids: a novel family of reusable catalysts?" Chemical Reviews, vol. 102, no. 10, pp. 3757-3778, 2002.

[4] V. Mévellec, A. Roucoux, E. Ramirez, K. Philippot, and B. Chaudret, "Surfactant-stabilized aqueous iridium(0) colloidal suspension: an efficient reusable catalyst for hydrogenation of arenes in biphasic media," Advanced Synthesis \& Catalysis, vol. 346, no. 1, pp. 72-76, 2004.

[5] J. Dupont and J. D. Scholten, "On the structural and surface properties of transition-metal nanoparticles in ionic liquids," Chemical Society Reviews, vol. 39, no. 5, pp. 1780-1804, 2010.

[6] P. Migowski and J. Dupont, "Catalytic applications of metal nanoparticles in imidazolium ionic liquids," Chemistry, vol. 13, no. 1, pp. 32-39, 2007.

[7] J. D. Scholten, B. C. Leal, and J. Dupont, "Transition metal nanoparticle catalysis in ionic liquids," ACS Catalysis, vol. 2, no. 1, pp. 184-200, 2012.

[8] X.-D. Mu, D. G. Evans, and Y. Kou, "A general method for preparation of PVP-stabilized noble metal nanoparticles in room temperature ionic liquids," Catalysis Letters, vol. 97, no. 3-4, pp. 151-154, 2004.

[9] J. D. Aiken III and R. G. Finke, "Polyoxoanion- and tetrabutylammonium-stabilized $\mathrm{Rh}(0)(\mathrm{n})$ nanoclusters: unprecedented nanocluster catalytic lifetime in solution," Journal of the American Chemical Society, vol. 121, no. 38, pp. 8803-8810, 1999.

[10] N. Gacemand and P. Diao, "Effect of solvent polarity on the assembly behavior of PVP coated rhodium nanoparticles," Colloids and Surfaces A, vol. 417, pp. 32-38, 2013.

[11] I. Miguel-García, A. Berenguer-Murcia, T. García, and D. Cazorla-Amorós, "Effect of the aging time of PVP coated palladium nanoparticles colloidal suspensions on their catalytic activity in the preferential oxidation of CO," Catalysis Today, vol. 187, no. 1, pp. 2-9, 2012.

[12] H. Song, R. M. Rioux, J. D. Hoefelmeyer et al., "Hydrothermal growth of mesoporous SBA-15 silica in the presence of PVPstabilized Pt nanoparticles: synthesis, characterization, and catalytic properties," Journal of the American Chemical Society, vol. 128, no. 9, pp. 3027-3037, 2006.

[13] P. S. Mdluli, N. M. Sosibo, P. N. Mashazi et al., "Selective adsorption of PVP on the surface of silver nanoparticles: a 
molecular dynamics study," Journal of Molecular Structure, vol. 1004, no. 1-3, pp. 131-137, 2011.

[14] S. W. Kang and Y. S. Kang, "Silver nanoparticles stabilized by crosslinked poly(vinyl pyrrolidone) and its application for facilitated olefin transport," Journal of Colloid and Interface Science, vol. 353, no. 1, pp. 83-86, 2011.

[15] N. Yan, Y. Yuan, and P. J. Dyson, "Rhodium nanoparticle catalysts stabilized with a polymer that enhances stability without compromising activity," Chemical Communications, vol. 47, no. 9, pp. 2529-2531, 2011.

[16] M. Liu, J. Zhang, J. Liu, and W. W. Yu, "Synthesis of PVPstabilized $\mathrm{Pt} / \mathrm{Ru}$ colloidal nanoparticles by ethanol reduction and their catalytic properties for selective hydrogenation of ortho-chloronitrobenzene," Journal of Catalysis, vol. 278, no. 1, pp. 1-7, 2011.

[17] V. L. Nguyen, M. Ohtaki, V. N. Ngo, M. T. Cao, and M. Nogami, "Structure and morphology of platinum nanoparticles with critical new issues of low high-index-facets," Advances in Natural Science, vol. 3, no. 2, pp. 1-4, 2012.

[18] V. L. Nguyen, D. C. Nguyen, H. Hirata, M. Ohtaki, T. Hayakawa, and M. Nogami, "Chemical synthesis and characterization of palladium nanoparticles," Advances in Natural Science, vol. 1, pp. $1-5,2010$.

[19] D. D. L. Martins, H. M. Alvarez, L. C. S. Aguiar, and O. A. C. Antunes, "Heck reactions catalyzed by $\mathrm{Pd}(0)$-PVP nanoparticles under conventional and microwave heating," Applied Catalysis A, vol. 408, no. 1-2, pp. 47-53, 2011.

[20] D. de Luna Martins, H. M. Alvarez, and L. C. S. Aguiar, "Microwave-assisted Suzuki reaction catalyzed by $\operatorname{Pd}(0)-P V P$ nanoparticles," Tetrahedron Letters, vol. 51, no. 52, pp. 6814-6817, 2010.

[21] M. A. Gelesky, S. S. X. Chiaro, F. A. Pavan, J. H. Z. Dos Santos, and J. Dupont, "Supported ionic liquid phase rhodium nanoparticle hydrogenation catalysts," Dalton Transactions, no. 47, pp. 5549-5553, 2007.

[22] M. A. Gelesky, C. W. Scheeren, L. Foppa, F. A. Pavan, S. L. P. Dias, and J. Dupont, "Metal nanoparticle/ionic liquid/cellulose: new catalytically active membrane materials for hydrogenation reactions," Biomacromolecules, vol. 10, no. 7, pp. 1888-1893, 2009.

[23] F. Durap, Ö. Metin, M. Aydemir, and S. Özkar, "New route to synthesis of PVP-stabilized palladium (0) nanoclusters and their enhanced catalytic activity in Heck and Suzuki cross-coupling reactions," Applied Organometallic Chemistry, vol. 23, no. 12, pp. 498-503, 2009.

[24] C. J. Brinker and G. W. Scherer, The Physics and Chemistry of Sol-Gel Processing, Academic Press, London, UK, 1990. 

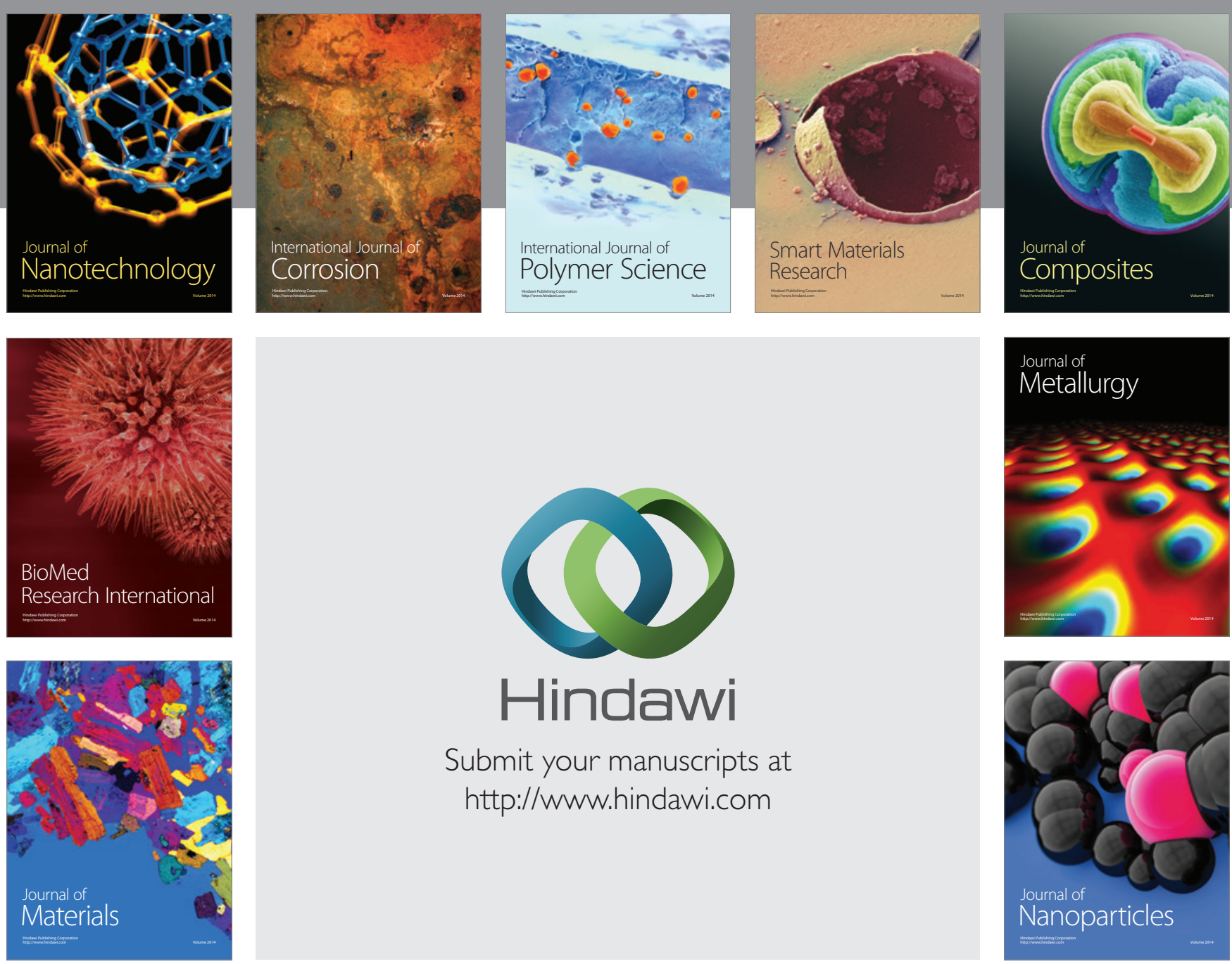

Submit your manuscripts at http://www.hindawi.com


\section{The Scientific World Journal}
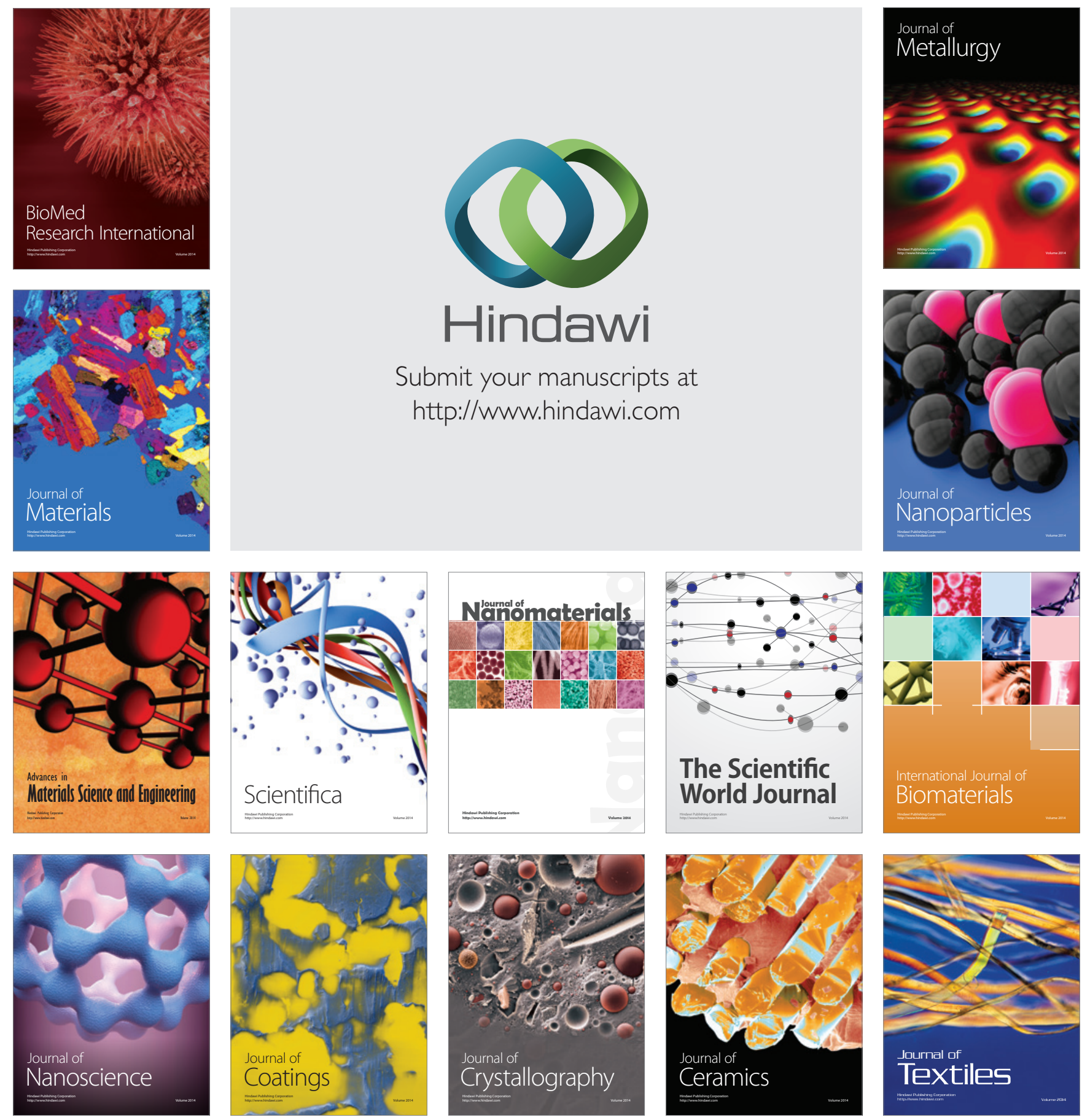